\title{
Phytoplankton Patchiness Generated by Long Internal Waves: A Model
}

\author{
M. Kahru \\ Department of the Baltic Sea, Institute of Thermophysics and Electrophysics, Paldiski St. 1, Tallinn 200 031, USSR
}

\begin{abstract}
A simple computer model is used to investigate the interaction between long internal waves (period $\sim 13 \mathrm{~d}$ ) and processes of primary productivity in the Baltic Sea. The periodic vertical displacements in or near the photic zone affect the availability of light and nutrients to primary producers, resulting in integral vertical fluxes of nutrients and biomass. If the nitrogen flux is parameterized implicitly by a diffusive flux across the halocline, the apparent coefficients of eddy diffusivity are more often negative and exceed in absolute value by 2 orders of magnitude the experimentally determined values. Differences in the depth integrals of daily primary production between wave crests and troughs amount to $\sim 50 \%$ and the vertical fiux of the nitrate nitrogen may locally reach $\sim 50 \mathrm{mg} \mathrm{N} \mathrm{m}{ }^{-2} \mathrm{~d}^{-1}$ The outlined mechanism might be a significant additional source for the formation of mesoscale horizontal heterogeneities in phytoplankton biomass.
\end{abstract}

\section{INTRODUCTION}

Quasi-synoptic spatial surveys of the mesoscale distribution of chlorophyll $a$ and hydrographic variables in the central Baltic Sea (Kahru et al., 1981; Kahru, 1982) showed striking variability of the chlorophyll field, much of which was sometimes clearly associated with patterns of the thermohaline layering. It was suggested that the locally increased phytoplankton biomass was caused by the vertical fluxes of nutrients due to the intensified vertical mixing on certain hydrographic conditions (shoaling of the halocline, narrowing of the intermediate layer). When expressed approximately in terms of nitrogen, the limiting nutrient for the phytoplankton, the chlorophyll contrasts over distances of $\sim 10 \mathrm{~km}$ were roughly equivalent to $\sim \operatorname{lg~N~m}{ }^{-2}$ for the upper 60-m layer. If the chlorophyll variability is to be explained by local mixing events across the halocline, and the vertical nitrogen flux is estimated as

$$
Q=-K_{2} \frac{\partial \mathrm{NO}_{3}}{\partial z}
$$

where $\mathrm{K}_{\mathrm{z}}=$ vertical eddy diffusivity; $\partial \mathrm{NO}_{3} / \partial \mathrm{z}=$ vertical nitrate gradient; diffusivities above $10^{-4} \mathrm{~m}^{2} \mathrm{~s}^{-1}$, at least locally and temporarily, should be postulated (Kahru, 1982). However, 2 orders of magnitude lower values were obtained by means of dye diffusion experiments in the Baltic halocline (Kullenberg, 1977). We may conjecture that dye diffusion experiments do not usually reveal the vigorous but intermittent mixing events caused by special weather conditions (Krauss, 1981) and/or special bottom topography (Shaffer, 1979). Here we examine quite the opposite possibility for the generation of mesoscale phytoplankton inhomogeneities, i.e. by means of vertical nutrient fluxes without any vertical mixing.

It has been suggested by a number of authors (e. $\mathrm{g}$. Woods, 1977) that the vertical turbulent transport of scalars deduced from bulk analysis may be effected by advection and mixing along inclined density surfaces. The intensity of these mechanisms peaks strongly at fronts. Moreover, Woods (1977) and Wroblewski and O'Brien (1981) have theoretically shown that a fluctuating velocity field in combination with non-conservative biological processes can give rise to apparent vertical diffusive fluxes without any vertical mixing. Actually, the coefficient of vertical eddy diffusivity, $\mathrm{K}_{\mathrm{z}}$ describes the intensity of vertical turbulent mixing due to motions on scales unresolved by the model. If advection is neglected, e.g. Eq. (1), $\mathrm{K}_{z}$ parametrically includes also the effects of any advective fluxes. The eddy diffusivity coefficient is derived as a proportionality coefficient from the 'gradient hypothesis' (Monin and Yaglom, 1971) relating the mean turbulent flux to the mean gradient. Let us consider a non-conservative variable $B$ with fluctuations $B^{\prime}$ and a mean vertical 
gradient $\frac{\partial \bar{B}}{\partial z}$. Then the mean vertical turbulent flux due to the vertical velocity fluctuations $\mathrm{w}^{\prime}$ is simply

$$
\overline{w^{\prime} B^{\prime}}=-K_{z} \frac{\partial \bar{B}}{\partial \mathrm{z}}
$$

If the vertical velocity fluctuations have time and space scales large enough to influence the rates and directions of biological processes during their lifetime, a mean flux arises which is uneffected by the mean gradient. Specifically, if B is the light-limited phytoplankton concentration and $w^{\prime}$ (with the $z$-axis directed upwards) represents vertical velocity fluctuations in the photic zone, the light-dependence of photosynthesis ensures that uplifts $\left(w^{\prime}>0\right)$ are preferentially accompanied by a local increase of $B\left(B^{\prime}>0\right)$, and, vice versa, sinking of a water parcel $\left(w^{\prime}<0\right)$ implies a higher probability of a concentration decrease $\left(B^{\prime}<0\right)$ in that parcel. It is assumed here that the vertical displacements have lifetimes sufficiently long for the biological effects to occur. The resulting mean upward flux $\left(\overline{w^{\prime} B^{\prime}}>0\right)$ cannot be derived from the mean vertical gradient. Depending on the sign of the mean gradient, the formally calculated vertical diffusivity, $K_{z}$ may acquire either positive or negative values (Wroblewski and O'Brien, 1981), or may lose even its formal definition if the mean gradient vanishes. The underlying mechanisms, however, are principally different from turbulent diffusion.

We are concerned here with the formation of vertical fluxes of non-conservative substances due to vertical undulations in the thermocline. Several observational studies have presented evidence for intense synopticscale $(\sim 20 \mathrm{~km})$ wave-like disturbances in the seasonal thermocline of the Baltic Sea. As the thermocline disturbances conceivably involve vertical displacements in or near the photosynthetic zone, they might have significant biological consequences. By means of a simple mathematical model it is shown that the vertical undulations in combination with primary production processes act as a pumping mechanism. If one tries to express the resultant nitrogen flux as an apparent diffusive flux, the formal vertical diffusivities must be assigned values significantly higher than experimentally measured for conservative substances. We believe that the localized forcing by the pumping mechanism might be a significant source for the biological variability. However, further observational studies of the physical-biological interactions are needed to verify this. The complexity of such measurements involving recurrent sampling of several physical, chemical and biological variables along extensive transects with fine spatial and temporal resolutions has forced us to use the model as a simple test stone.

Similar problems of interaction between semidiumal internal tides and plankton biology have been dealt with by Kamykowski $(1974,1978,1981)$ with special emphasis on planktonic vertical migrations. Here we concentrate on some other aspects e.g. the apparent vertical fluxes, with a special emphasis on observations in the Baltic Sea. Due to the much longer wave period considered here, the phase relationships between the internal wave and the planktonic diurnal processes are not so important.

\section{PHYSICAL EVIDENCE FOR SYNOPTIC-SCALE WAVE-LIKE DISTURBANCES IN THE BALTIC THERMOCLINE}

Pronounced variability of the Baltic thermocline on synoptic and smaller scales has been repeatedly reported by various groups studying the Baltic thermohaline variability. For example, Kielman et al. (1973), towing a thermistor chain, discovered an obviously regular pattern of isotherm displacements in the Western Gotland Basin. The wave-like structures with 5 distinguishable peaks extended over the thermocline layer ( $\sim 15$ to $30 \mathrm{~m}$ ) and were characterized by wave heights of $\sim 15 \mathrm{~m}$ and wavelengths of approximately $29 \mathrm{~km}$. Although there was no information on the frequency, the authors considered it likely that an internal wave of that wavelength might be an internal seiche.
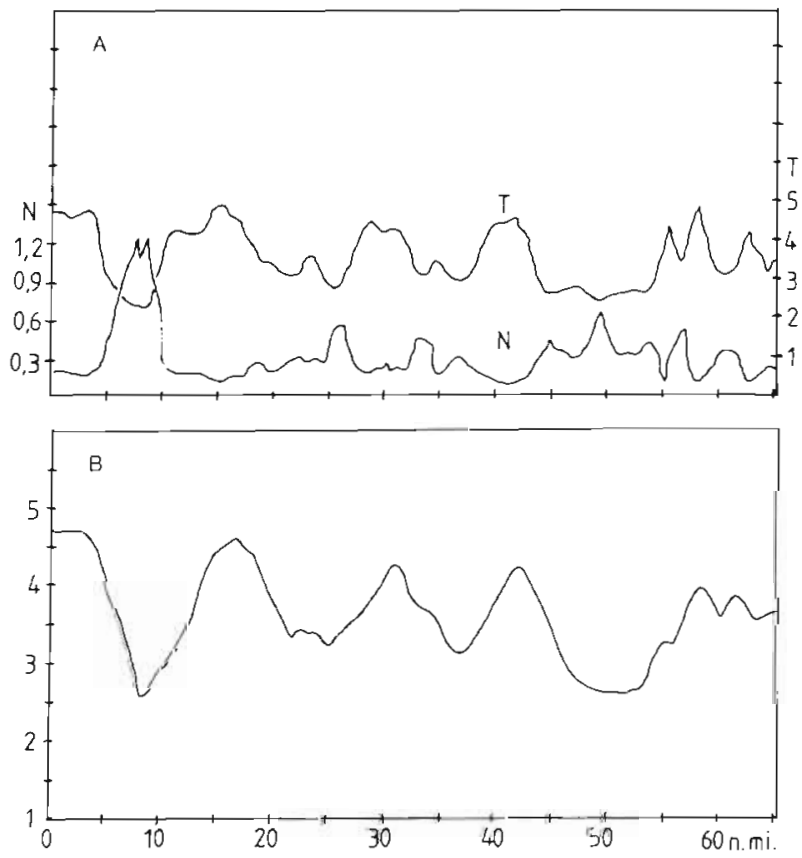

Fig. 1. (A) Horizontal profiles of temperature $\left(\mathrm{T},{ }^{\circ} \mathrm{C}\right)$ and nitrate $\left(\mathrm{N}, \mathrm{mmol} \mathrm{N} \mathrm{m}{ }^{-3}\right.$ ) along a transect at $30 \mathrm{~m}$ depth; $(B)$ the same temperature profile after smoothing with floating averages over 30 samples. Slightly abridged from Grasshoff and Hansen (1980) 
Magaard and Keunecke (1975), again using the towed thermistor chain, observed a bell-like vertical displacement $(-15 \mathrm{~m})$ of the isotherms around the mean depth of $\sim 20 \mathrm{~m}$. The disturbance had horizontal dimensions of $\sim 30 \mathrm{~km}$ and was interpreted by the authors as a synoptic-scale eddy.

A most interesting data set was obtained by Grasshoff and Hansen (1980) with a towed chemical-physical profiling system. As a part of their extensive sampling program they obtained an 80 -nautical mile section on the 30-m depth level through the Southern Baltic Proper. Their spatial resolution of $\sim 300 \mathrm{~m}$ was adequate to show a close covariability of even the finescale structures of most of the chemical parameters ( $\mathrm{pH}$, nitrate, silicate, etc.) with temperature (Fig. 1). This covariablility was due to vertical displacements in strong vertical gradients of most of the variables. The vertical stratification showed typical features of the Central Baltic: (1) a warm surface layer, (2) the cold intermediate layer, which had been formed by the winter convection, and (3) the saline lower layer of the Kattegatt water. However, the thermocline was still weakly developed and the density differences between the upper layer (excluding the top $10 \mathrm{~m}$ ) and the intermediate layer were minimal. As a consequence, only small amounts of energy were needed to lift the water from about $50 \mathrm{~m}$ to $30 \mathrm{~m}$. The profile showed a series of quite regular, wave-like oscillations of temperature and the chemical variables. A single 'crest' was observed to propagate at a phase speed of $1.85 \mathrm{~km} \mathrm{~d}^{-1}$. After a slight smoothing with floating averages the following parameters of the undulations were estimated: wavelength $\sim 24 \pm 5 \mathrm{~km}$ (over 5 peaks), wave height $\sim 25 \pm 10 \mathrm{~m}$, period $\sim 13.3 \pm 1.5 \mathrm{~d}$. The causal physical mechanism of the undulations remains elusive; however, the estimated period clearly excludes common gravitational internal waves which cannot have periods longer than the local inertial period $(\sim 14 \mathrm{~h})$. The undulations clearly belong to the synoptic-scale phenomena and may be related to synoptic-scale eddies. Synoptic eddies are shown to be a dominant feature of the Baltic Sea variability (Aitsam and Elken, 1982). Inhomogeneities of the upper layers, often having a form of vertical isotherm undulations, have been frequently observed on our 'Batfish' traces (Aitsam and Pavelson, 1982) but more often the disturbances lack a dominant wavelength and present a mixture of various wavelengths. Some of the inhomogeneities are density-compensated (intrusion-like) and of non-wave origin.

Even though the underlying physical mechanisms of the vertical undulations may be variable and not yet clearly understood, these displacements must have significant biological consequences. Actually, for the simple biological-physical model presented here the causal physical mechanism is presumably irrelevant. Hence, an ideal sinusoidal internal wave is used to model the vertical displacements.

\section{DESCRIPTION OF THE MODEL}

The internal wave field in a 2-layer water column of $100 \mathrm{~m}$ depth was modeled (Kamykowski, 1974) by expressing the time dependence of the vertical velocity above the interface,

$$
w=\frac{z}{E} A \omega \cos (\omega t)
$$

and below the interface,

$$
w=-\frac{E+H+z}{H} A \omega \cos (\omega t)
$$

Symbols and parameter values are given in Table 1. Parameter values were chosen to simulate the observations of Grasshoff and Hansen (1980). The model vertical structure is given by a grid of 26 points displaced

\begin{tabular}{|c|c|c|}
\hline Parameter and units & Symbol & Value used \\
\hline Depth, m & & 100 \\
\hline Mean thickness of the upper layer, $m$ & $\mathrm{E}$ & 30 \\
\hline Mean thickness of the lower layer, $m$ & $\mathrm{H}$ & 70 \\
\hline Maximal wave amplitude, $\mathrm{m}$ & $\mathrm{A}$ & 10 \\
\hline Wave period, d & $\mathrm{T}$ & 13 \\
\hline Wave frequency, $\mathrm{d}^{-1}$ & $\omega$ & 0.48 \\
\hline PAR immediately below the surface, $\mathrm{W} \mathrm{m} \mathrm{m}^{-2}$ & & 255 \\
\hline Vertical attenuation coefficient for PAR, $\mathrm{m}^{-1}$ & & 0.185 \\
\hline Half-saturation constant for nitrogen uptake, mmol $\mathrm{N} \mathrm{m}^{-3}$ & & 0.6 \\
\hline Maximum potential photosynthetic rate, $\mathrm{mg} \mathrm{C}(\mathrm{mg} \mathrm{Chl})^{-1} \mathrm{~h}^{-1}$ & $\mathrm{P}_{\mathrm{s}}^{\mathrm{B}}$ & 12 \\
\hline Initial slope of the photosynthesis/light curve, $\mathrm{mg} \mathrm{C}(\mathrm{mg} \mathrm{Chl})^{-1} \mathrm{~h}^{-1} \mathrm{~W}^{-1} \mathrm{~m}^{2}$ & $a$ & 0.2 \\
\hline Parameter of photoinhibition, mg $\mathrm{C}(\mathrm{mg} \mathrm{Chl})^{-1} \mathrm{~h}^{-1} \mathrm{~W}^{-1} \mathrm{~m}^{2}$ & $\beta$ & 0.03 \\
\hline
\end{tabular}

Table 1. Parameters, units and values used in the model 


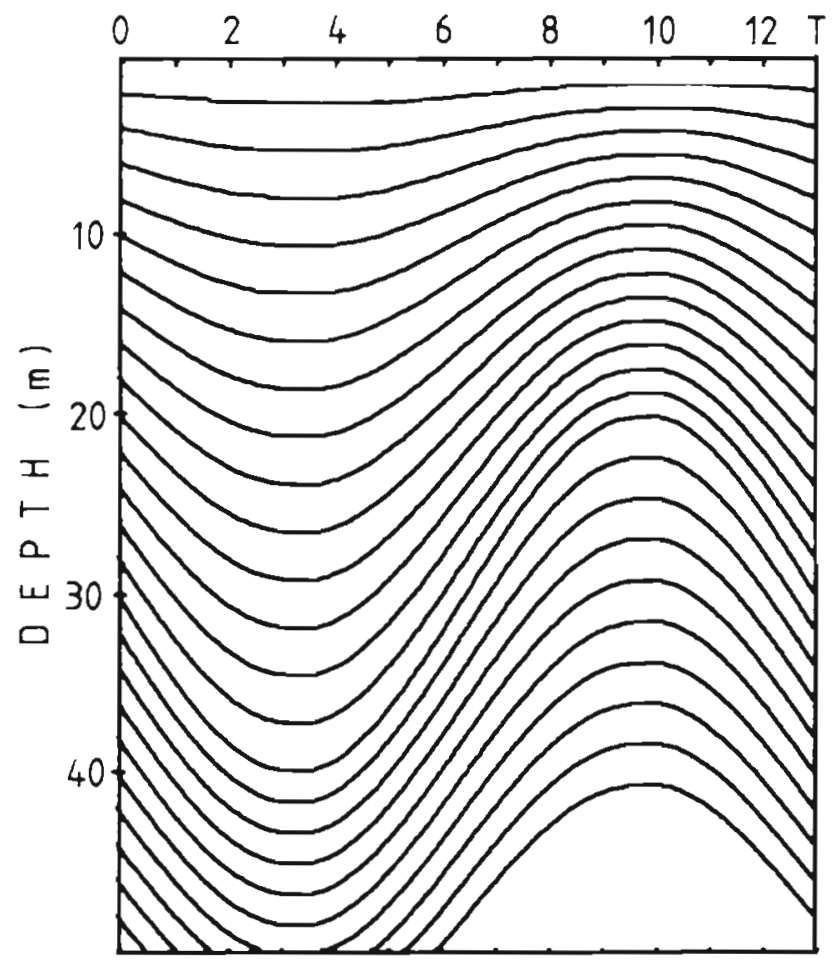

Fig. 2. Vertical displacements of the grid by the internal wave

vertically by the internal wave (Fig. 2). The grid extends from the surface to a mean depth of $50 \mathrm{~m}$. Every grid point is associated with a parcel of water containing phytoplankton and nutrients. The phytoplankton biomass in a parcel is given by the chlorophyll a concentration. It is assumed that nitrates (more correctly, the sum of nitrates, nitrites and ammonia) represent the source of the limiting nutrient. In comparison with other models for phytoplankton growth (e.g. Wroblewski, 1977), the model is simplified in several aspects. It ignores vertical mixing as well as horizontal heterogeneities. Averaging (Eq. [2]) is performed over the entire wave period. Hence, the internal wave velocities given by Eqs. $(3,4)$ appear as the velocity fluctuations $w^{\prime}$. Similarly, the biological dynamics is assumed to be balanced on the mean. depth level and fluctuations in the phytoplankton, and nitrate stocks are solely due to the effects of the vertical displacements. In essence, only the fluctuations from the means $\left(B^{\prime}[t]=B[t]-\bar{B}\right)$ are modeled explicitly; i. e. the mean vertical profiles of chlorophyll and nitrates are held fixed during each model run for 1 wave period. Only the fluctuations of the concentrations are found by evaluating the enhancement or restriction of the phytoplankton growth in relation to the mean depth level of a water parcel. This is accomplished by integrating the difference between the rates of primary production on the mean level and on the undulating level over 1 half wave period. As the phytoplankton chemical composition is assumed to be fixed according to the carbon : nitrogen : chlorophyll ratios of $50: 8: 1$, the nitrate dynamics is solely determined by the algal uptake and is calculated from the phytoplankton growth. The excess or deficient amounts of biomass or nitrate in comparison to the balanced dynamics on the mean depth level are multiplied by the respective mean vertical velocities during a half period. These products of $\overline{w^{\prime} B^{\prime}}$ are then averaged over a wave crest and a trough to get the mean vertical fluxes due to the vertical displacements by the wave.

The biological part of the model is based on a new empirical relationship between photosynthesis (carbon assimilation rate per unit chlorophyil) and light in marine phytoplankton (Platt et al., 1980):

$$
\mathrm{P}^{\mathrm{B}}=\mathrm{P}_{\mathrm{s}}^{\mathrm{B}}\left(1-\mathrm{e}^{-\mathrm{a}}\right) \mathrm{e}^{-\mathrm{b}}
$$

where $\mathrm{P}_{\mathrm{s}}{ }^{\mathrm{B}}=$ potential maximal photosynthetic rate; $\mathrm{a}=\alpha \mathrm{I} / \mathrm{P}_{\mathrm{s}}{ }^{\mathrm{B}} ; \quad \mathrm{b}=\beta \mathrm{I} / \mathrm{P}_{\mathrm{s}}{ }^{\mathrm{B}} ; \mathrm{I}=$ photosynthetic available radiant energy (PAR); $\alpha$ and $\beta=$ respectively, initial slope and parameter of photoinhibition. Diurnal changes in PAR are given by a simple sinusoidal curve with a $16 \mathrm{~h} / 8 \mathrm{~h}$ light/dark cycle. The integration timestep is $1 \mathrm{~h}$. The depth dependence of irradiance is treated as a simple exponential function with a constant attenuation coefficient; i. e. the phytoplankton self-shading is not modeled. The parameter values for the photosynthesis model were fitted to suit experiments in the Baltic Sea (Gargas et al., 1979) and the observed photoinhibition in the top 2-m layer (Sjöberg and Wilmot, 1977). The nutrient control of phytoplankton growth is described by the familiar MichaelisMenten curve (Dugdale, 1967) and the mutual control of growth by the available nitrogen and light is considered to be multiplicative (Fig. 3).

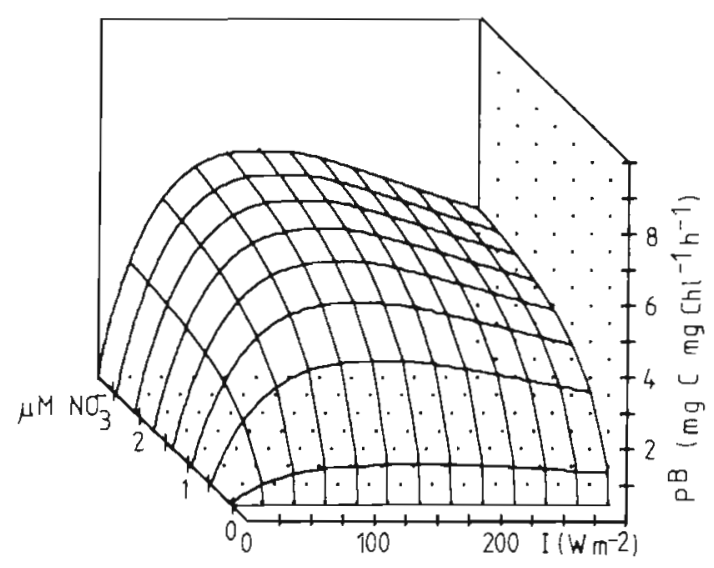

Fig. 3. Combined control of phytoplankton growth by light and nitrogen 


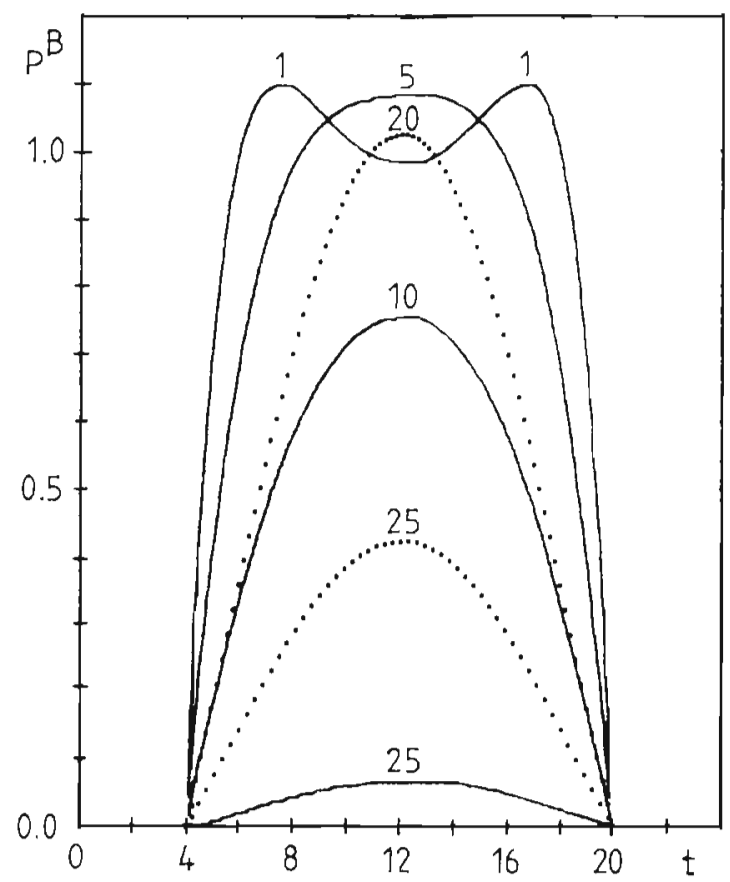

Fig. 4. Daily variation of the photosynthetic rate at selected depths (in $\mathrm{m}$ ) depending on the nitrate concentration: $0.1 \mathrm{mmol} \mathrm{N} \mathrm{m}{ }^{-3}$ (continuous curves) and $4 \mathrm{mmol} \mathrm{N} \mathrm{m}{ }^{-3}$ (dotted curves)

\section{RESULTS AND DISCUSSION}

The model was run with a large number of different initial vertical distributions of chlorophyll and nitrate. The results were, however, usually qualitatively similar and only a few typical examples are presented here. The chlorophyll profiles are generalized forms of our own data (e. g. Kahru et al., 1981), the nitrate profiles are due to various sources. After the spring phytoplankton bloom the upper layers are almost depleted of the available inorganic nitrogen; a sharp increase, most notable in nitrate, occurs in the top of the lower, saline layer. Sometimes the intermediate layer may show a double-layered substructure with an upper, nutrient-poor sub-layer and a lower, nutrient-rich sublayer (Grasshoff and Hansen, 1980). The relatively minor density differences in the intermediate layer facilitate an uplift of the nutrients into the photic zone, either by means of internal waves or by vertical mixing. Such an uplift may cause a dramatic effect on the primary productivity (Fig. 4). The exact depth where the intermediate layer productivity may exceed the near-surface productivity depends crucially on the exact parameter values, especially on the vertical attenuation coefficient; the present model suggests it might occur between 15 and 20 m. Fig. 5 displays the
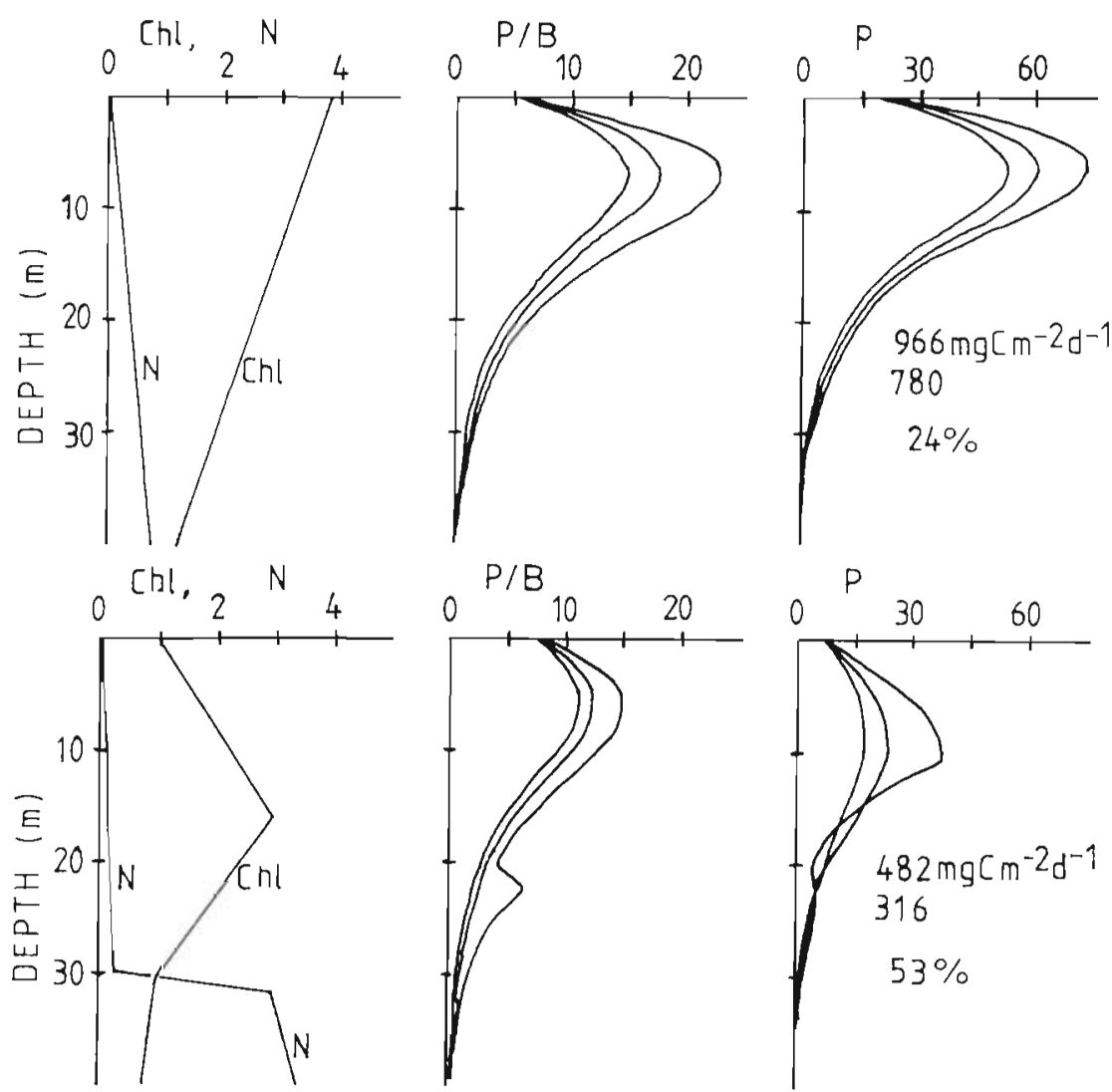

Fig. 5. Depth profiles of chlorophyll a (Chl, $\mathrm{mg} \mathrm{m}^{-3}$ ), nitrate ( $\mathrm{N}, \mathrm{mmol} \mathrm{N} \mathrm{m}^{-3}$ ) normalized daily primary production $\left(\mathrm{P} / \mathrm{B}, \mathrm{mg} \mathrm{C}\left[\mathrm{mg} \mathrm{Chl}^{-1} \mathrm{~d}^{-1}\right)\right.$ and daily primary production $\left(P, \mathrm{mg} \mathrm{C} \mathrm{m} \mathrm{m}^{-3} \mathrm{~d}^{-1}\right.$ ). The 3 curves correspond (from left ro right) to wave trough, mean depth, and wave crest conditions. The set-up corresponds to spring bloom (A) and to nutrient enriched sub-layer after the bloom (B). Column productions in wave crest (upper) and trough (lower), as well as the difference in $\%$ are also indicated 
influence of the internal wave on the column primary productivity on 2 typical situations: (A) a weak stratification during the spring bloom, and (B) with the nutrient-rich sub-layer after the spring bloom. The depth integrals of the daily primary production corresponding to the extreme phases of the internal wave (crest vs. trough) may exhibit more than $50 \%$-contrasts. The associated vertical flux of the nitrate nitrogen due to the wave action and biological dynamics may locally attain values of around $-50 \mathrm{mg} \mathrm{N} \mathrm{m}^{-2} \mathrm{~d}^{-1}$ (Fig. 6). The
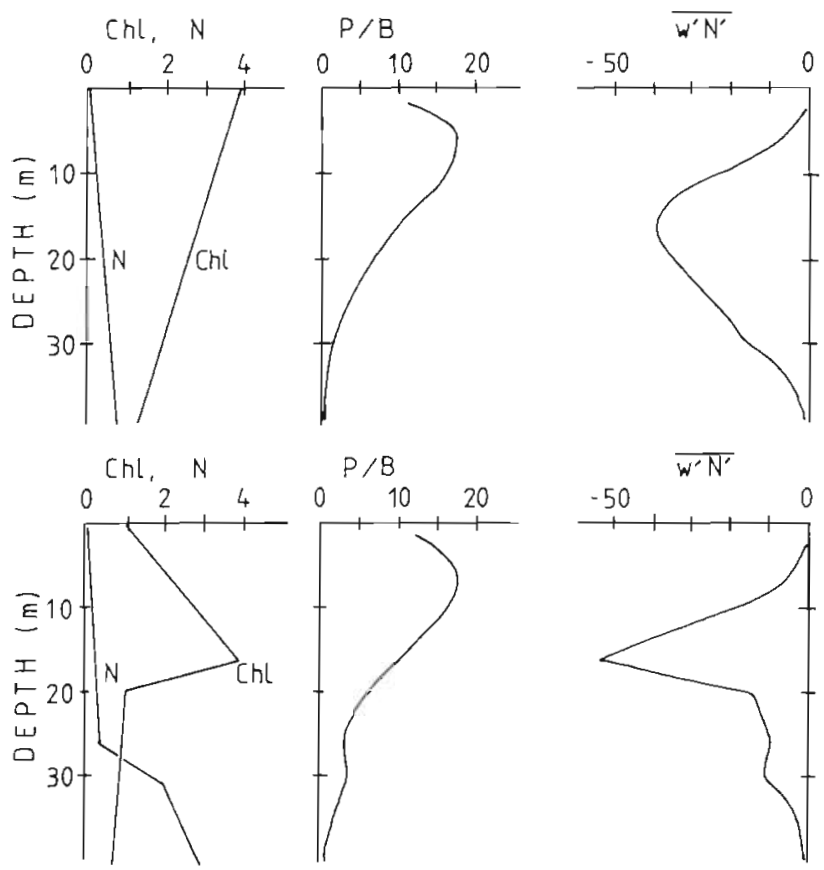

Fig. 6. Depth profiles of the simulated vertical flux of nitrate nitrogen, $\overline{w^{\prime} N^{\prime}}\left(\mathrm{mg} \mathrm{N} \mathrm{m}^{-2} \mathrm{~d}^{-1}\right)$ in relation to chlorophyll $a_{\text {, }}$ nitrate and normalized mean daily primary production

minus sign does not mean a downward transport of the nitrates; it represents the integral effects of the net transfers towards the phytoplankton biomass in the uplifted water and net transfers towards dissolved nitrogen in the sunken water. If one had tried to parameterize the nitrogen flux to the phytoplankton as a diffusive flux of nitrate across the nutricline using the mean vertical gradient of $3 \mathrm{mg} \mathrm{N} \mathrm{m}^{-3} / \mathrm{m}$ for the halocline, the apparent vertical diffusivity would have been $2 \mathrm{~cm}^{2} \mathrm{~s}^{-1}$ or by a factor of 100 times above the value of Kullenberg (1977).

As could be seen easily from the model description, the model is not intended to give accurate predictions of the distribution of biomass and nutrients. Instead, a single mechanism is extracted from the real-world complexity, and studied separately. In order to calculate the biomass fluctuations we found it more secure not to involve speculations about other modifying mechanisms, e. g. grazing and sinking of the algae. Ignoring other sources of fluctuations is roughly equivalent to assuming that these sources act more or less randomly in respect to the wave actions, and cancel each other in the average. As the mean biomass (and nutrient) dynamics itself was not modeled explicitly, we cannot determine the duration of the enhanced growth in the uplifted water, i. e. the commencement of the nitrate depletion. Thus, it is not possible to find the amplitudes of the resulting mesoscale biomass inhomogeneities. By the same reasons it is unreliable to evaluate the effects of horizontal mixing.

The horizontal concentration stripes corresponding to the wave crests and troughs will probably be smoothed and distorted by horizontal processes but, nonetheless, the pumping mechanism should act comparatively independently. The physical model used is clearly a gross simplification but it seems premature to use more sophisticated models for the purpose of the present paper as so little is known about the actual trajectories of individual phytoplankters (water parcels). With the present model the path followed by a single water parcel over 1 period describes an ellipse perpendicular to the wave direction. The horizontal component of transport due to the convergences and divergences in the wave has a modifying effect on the actual distributions but does not influence the computed vertical fluxes. Fortunately, the model is not sensitive to the least known parameter, the wave period, as increasing or decreasing the period has opposite effects on the 2 components of the products $\mathrm{w}^{\prime} \mathrm{B}^{\prime}$ which more or less cancel each other.

The 2 distinguished mechanisms for the upward transport of nutrients, vertical mixing and wave pumping, are in fact not mutually exclusive. Intense mixing on the halocline level is conceivably confined to topographic boundaries (Shaffer, 1979). The newly formed enriched layers rise and spread isopycnally, and may be finally subjected to the internal wave action. Also, after being transferred into the intermediate layer on topographic contacts, there appear more possibilities for the nutrients to reach the upper layers and become available to phytoplankton. This might occur as a result of intense mixing events in the shear zones created by inertial waves (Krauss, 1981).

\section{CONCLUSION}

We have modeled the interactions between synoptic-scale internal undulations in the thermocline and phytoplankton-nutrient dynamics. It has been shown that the effects of the undulations may be parametrically disguised as an apparent vertical diffusive flux of 
substances, e. g. of nitrogen. Numerically the apparent diffusivities may exceed by up to 2 orders of magnitude the 'real' diffusivities in the halocline. However, the underlying mechanism is principally different from turbulent diffusion. Hence, the one-dimensional vertical eddy diffusivity concept should be used cautiously for time scales longer than a few hours. The internal undulations with wavelengths of $\sim 20 \mathrm{~km}$ may be one of the sources for the intense mesoscale phytoplankton and nutrient patchiness in the Baltic Sea.

Acknowledgements. I thank Professor A. Aitsam and J. Elken for helpful discussions and H. P. Hansen for permission to reproduce Fig. 1. The comments by Dr. J. H. Steele are gratefully acknowledged.

\section{LITERATURE CITED}

Aitsam, A., Elken, J. (1982). Synoptic scale variability of hydrophysical fields in the Baltic Proper on the basis of CTD measurements. In: Nihoul, J. C. J. (ed.) Hydrodynamics of semi-enclosed seas. Elsevier, Amsterdam, pp. $433-468$

Aitsam, A., Pavelson, J. (1982). The variability of the temperature, salinity and density fields in the upper layers of the Baltic Sea. In: Nihoul, J. C. J. (ed.) Hydrodynamics of semi-enclosed seas. Elsevier, Amsterdam, pp. 489-502

Dugdale, R. C. (1967). Nutrient limitation in the sea: dynamics, identification and significance. Limnol. Oceanogr. 12: 685-695

Gargas, E., Hare, I., Martens, P., Edler, L. (1979). Diel changes in phytoplankton photosynthetic efficiency in brackish waters. Mar. Biol. 52: 113-122

Grasshoff, K., Hansen, H. P. (1980). Small-scale variability of chemical parameters in the Baltic. Coun. Meet. int. Coun. Explor. Sea C.M-ICESIC: 8

Kahru, M. (1982). The influence of hydrodynamics on the chlorophyll field in the open Baltic. In: Nihoul, J. C. J. (ed.) Hydrodynamics of semi-enclosed seas. Elsevier, Amsterdam, pp. 531-542
Kahru, M., Aitsam, A., Elken, J. (1981). Coarse-scale spatial structure of phytoplankton standing crop in relation to hydrography in the open Baltic Sea. Mar. Ecol. Prog. Ser. 5: $311-318$

Kamykowski, D. (1974). Possible interactions between phytoplankton and semidiurnal internal tides. J. mar. Res. 32 $67-89$

Kamykowski, D. (1978). Organism patchiness in lakes resulting from the interaction between the internal seiche and planktonic diurnal vertical migration. Ecol. Modelling 4: $197-210$

Kamykowski, D. (1981). The simulation of a southern California red tide using characteristics of a simultaneously measured internal wave field. Ecol. Modelling 12: 253-265

Kielmann, J., Krauss, W., Keunecke, K.-H. (1973). Currents and stratification in the Belt Sea and the Arkona Basin during 1962-1968. Kieler Meeresforsch. 29: 90-111

Krauss, W. (1981). The erosion of a thermocline. J. Phys. Oceanogr. 11: 415-433

Kullenberg, G. E. B. (1977). Observations of the mixing in the Baltic thermo- and halocline layers. Tellus 29:572-587

Magaard, L., Keunecke, K.-H. (1975). Measurements by means of towed thermistor cables and problems of their interpretation with respect to mesoscale processes. Mem. Soc. Roy. Sci. de Liège, Ser. 6, 7: 147-160

Monin, A. S., Yaglom, A. M. (1971). Statistical fluid mechanics, Vol. 1, MIT Press, Cambridge, USA

Platt, T., Gallegos, C. L., Harrison, W. G. (1980). Photoinhibition of photosynthesis in natural assemblages of marine phytoplankton. J. mar. Res. 38: 687-701

Shaffer, G. (1979). On the phosphorus and oxygen dynamics of the Baltic Sea. Contrib. Askö Lab., Univ. Stockholm 26: $1-90$

Sjöberg, S., Wilmot, W. (1977). System analysis of a spring phytoplankton bloom in the Baltic. Contrib. Askö Lab., Univ. Stockholm 20: 1-99

Woods, J. D. (1977). Parameterization of unresolved motions. In: Kraus, E. B. (ed.) Modelling and prediction of the upper layers of the ocean. Pergamon Press, Oxford, p. 118-140

Wroblewski, J. S. (1977). A model of phytoplankton bloom formation during variable Oregon upwelling. J. mar. Res. 35: 357-394

Wroblewski, J. S., O'Brien, J. J. (1981). On modeling the turbulent transport of passive biological variables in aquatic ecosystems. Ecol. Modelling 12: 29-44 